\title{
XII. Observations on M. Laplace's Communication to the Royal Academy of Sciences, "Sur l'Attraction des Sphères, et sur la Répulsion des Fluides élastiques"
}

\author{
John Herapath Esq.
}

To cite this article: John Herapath Esq. (1823) XII. Observations on M. Laplace's Communication to the Royal Academy of Sciences, "Sur l'Attraction des Sphères, et sur la Répulsion des Fluides élastiques", Philosophical Magazine Series 1, 62:303, 61-66, DOI: 10.1080/14786442308644376

To link to this article: http://dx.doi.org/10.1080/14786442308644376

$$
\text { 曲 Published online: } 23 \text { Jul } 2009 .
$$

Submit your article to this journal ए]

$$
\text { Џll Article views: } 2
$$

Q View related articles $\longleftarrow$ 


\section{$\left[\begin{array}{ll}6 & 1\end{array}\right]$}

XII. Observations on M. Laplace's Communication to the Royal Acadcmy of Sciences, "Sur l'Attraction des Sphères, et sur la Répulsion des Fluides élastiques." By John Herrapatri, Esq.

O $\mathrm{N}$ the first of May 1821, I published in the Annals of Philosophy a theory of gaseous bodies, mathematically drawn from the Newtonian theory of heat. An announcement of the publication and objects of the paper which contained this theory, and which had been in the hands of the principal members of the Royal Society from the Mar preceding, was sent to the Marquis de Laplace in June 182i. On the 10th of the following September, this nobleman communicated to the Royal Academy of Sciences a paper, whose professed object is to demonstrate from the principles of caloric the known laws of permanent airs, - the same that my paper contained. Unfortunately I did not meet with M. Laplace's paper until towards the fall of 1822; at which time I first saw it in the Connaissance des Tems for 1824.

Though it was obvious from the perfect coincidence of the object of M. Laplace's paper with that of a part of mine, and its being presented to the Royal Academy so long after the printing and notice of my paper, that his communication was in consequence of mine and intended to supersede it, yet $\mathbf{I}$ preferred leaving some instances of arguments and results, which appeared to me in point of accuracy to be exceptionable, to the comments of others, to making any observations on them myself. Perceiving, however, by the Connaissance des Tems for 1825, which I have lately received, that M. Laplace has in that work as good as four papers in continuation of his first; and that he has excited such an interest in the French Board of Longitude, as to induce that body to issue a commission to repeat some experiments on sound, for the purpose of affording him the advantage of better results; I have thought it necessary to throw together a few remarks, which may enable philosophers more easily to estimate the success of M. Laplace's investigations.

In the views of corpuscular repulsion of airs, which Newton proposed to philosophers to examine, he imagined that the repulsion of each particle extends to those particles only which immediately surround it. The reason, if a reason it can be called, which I believe he assigns for this limitation, is the similarity of a phænomenon in magnetic attraction. Without entering into a discussion of the difference of those phænomena, which are as different and dissimilar as they can well be, 
it may be said that explanations by analogy are in most physical cases illusive and deceitful, and in all unsatisfactory. M. Laplace therefore, discarding the limitation of Newton, proceeds to determine the laws of elastic fluids on the supposition of the corpuscular repulsion being sensible at insensible, and insensible at sensible distances. Each particle of a fluid which is at a sensible distance from the envelope, is on this hypothesis kept in equilibrio by the balance of repulsion in the surrounding particles. This repulsion he first assumes exclusively due to the caloric of the particles; their mutual distances being such, though insensibly small, that their reciprocal attraction has no sensible effect. In the general equation therefore of a fluid sphere, $d p=\rho \phi d r$ in which $\phi$ is the repulsion of the whole sphere of the density $p$ on a point at the distance $r$ from its centre, and $p$ the pressure in an opposite direction to the repulsion, M. Laplace conceives $\Phi=0$; which gives $p=$ constant.

So far I apprehend no great objection would be made to M. Laplace's assumptions; though some of them are certainly not unexceptionable. His statement however, that " en nommant $r$ la distance mutuelle de deux molécules de gaz, nous exprimerons la loi de répulsion par $\mathrm{H} c^{2} \Phi(r)$," $\$(r)$ being insensible with a sensible value to $r$, and $H$ being a constant, we cannot $I$ think so easily admit. For since the particles of caloric are supposed to have a mutually repulsive force, and each particle of the gas to retain by its attraction its caloric, the caloric must assume about a particle of the gas, the form of a sphere or spherical shell. Nor would the repulsion of the surrounding particles have any effect on the figure, unless to promote or preserve it. Supposing therefore the distance $r$ between the particles to remain the same, the function $\varphi(r)$ must involve the dimensions of the spheres or shells; consequently, as these dimensions would vary with the quantity of caloric, the repulsion would not be as $c^{\mathbb{Z}}$, as M. Laplace conceives; unless when the particles of caloric mutually repel one another by a force reciprocally proportional to the square of the distance, which would give the gas a very different law to that which experiment requires.

Conceding to M. Laplace the above law, which $I$ think it is plain cannot be correct, he finds by some ingenious considerations, $P$ being the pressure on any point, and $2 \pi \mathrm{HK}$ an invariable factor, that

$$
\mathrm{P}=2 \pi \mathrm{H} \mathrm{K} \rho^{2} c^{2} ; \quad \text { (1) }
$$

a theorem which of itself expresses nothing that $I$ know of in the laws of gases. 
This theorem, combined with another which he immediately deduces, includes, he says," les lois générales des fluides élastiques."

"Let us imagine," proceeds M. Laplace, "that the envelope and the contained gas have a common temperature $t$. It is manifest that any molecule whatever of this gas will every instant be struck by some of the calorific rays emitted by the surrounding bodies. A part of these rays it will stifle; but to maintain the temperature unchanged, it must radiate as many rays as it stifles. In any other space of the same temperature the molecule will be struck by the same quantity of calorific rays; the same part of which as before it will absorb and replace by its radiation. The quantity of calorific rays therefore which any given surface at every instant receives, is some function of the temperature alone, and independent of the surrounding bodies: I shall denote it by $\Pi(t)$. Hence the extinction will be $q \Pi(t), q$ being a constant factor depending on the nature of the molecule or of the gas. I will here observe that the quantity of rays emitted by the surrounding bodies, and which constitutes the free caloric of space, is, on account of the extreme velocity we must necessarily assign those rays, but a very insensible part of their whole caloric; which is otherwise manifest from the experiments made to condense it. Now in whatever manner the caloric of the surrounding molecules acts by its repulsion on the caloric of any particular molecule of gas, to detach a part of this caloric and make the molecule radiate, it is evident that this radiation will be in a ratio compounded of the density of the gas surrounding the molecule, or of $\rho c$ and the caloric $c$ contained in the molecule. It will

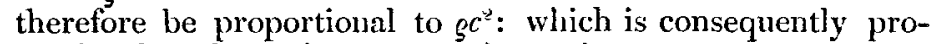
portional to the extincton $q \Pi(t)$; so that we may suppose,

$$
\rho c^{2}=q^{\prime} I I(t) ; \quad(2)
$$

$q^{\prime}$ being a constant factor depending on the nature of the gas, and $\Pi(t)$ a function of the temperature independent of this nature."

These are the arguments by which M. Laplace attempts to establish his equation 2 . If for the sake of brevity we pass over the first conclusion, namely, that the radiation to the molecule is independent of the surrounding bodies and some function of $t$, which if rigidly considered is probably not so evident as M. Laplace seems to think it; philosophers will, I presume, hardly then grant the latter conclusion, that the radiation of a molecule is proportional to $\rho c \times c$. We might also easily show that surrounding molecules tend rather by their repulsion to compress the caloric of an inclosed molecule closer towards the centre, than to disperse it; but this too we 
will pass over. Granting that the caloric of the surrounding molecules acts in some way by its repulsion to make the central molecule radiate, it is plain by the course $M$. Laplace himself takes, that he consider's this action proportional to the quantity of caloric acted on, and to the intensity of repulsion of the surrounding caloric. The radiation must therefore be as $c \times \rho c \phi(r)$ nearly ${ }^{*} ; r$ being the distance of two molecules, and $p(r)$ the intensity of repulsion of a particle of caloric at the distance $r$. But $a$ being some constant $\gamma=\sqrt[3]{\frac{a}{\xi}}$; and therefore by M. Laplace's own principles his equation 2 should be,

$$
\rho \mathrm{c}^{9} \phi\left(\sqrt[3]{\frac{a}{\varphi}}\right)=q^{\prime} \Pi(t)
$$

instead of,

$$
\rho c^{3}=q^{\prime} \Pi(t) \text {. }
$$

In the third part of his paper, M. Laplace introduces the function $\phi(r)$; but drops it in the final equation without giving any reason whatever. From what I can perceive, he seems to involve it in the constaint coefficient $q$. If so, it appears to me to be utterly repugnant to his own principles and definition of this supposed constant; for he distinctly tells us that $q$ is " un facteur constant dépendant de la nature de la molécule ou da gaz;" and therefore it ought to be the same for every density of the same gas; since neither the nature of the molecule or gas is changed by a change of density.

It is the elror of neglecting this function which has enabled the marquis to bring out his conclusions independently of the law of repulsion in his 2 nd part, and of the laws of repulsion and attraction in the 3rd part-conclusions which at the first glance of his paper forcibly struck me as strongly indicative of errors somewhere. That we are not justified in neglecting that part of $\mathbf{A}$ which depends on $p r$, will appear from the consideration, that a molecule of gas is made, by M. Laplace's views, to radiate its caloric by the repulsion of the caloric of other molecules surrounding that molecule. And as he assumes that this sphere of repulsion is insensibly small, the entire action of the whole molecules within this sphere must be some function of $r$, the distance of two molecules; and therefore some function of the density $\rho$.

Equation A combined with 1, would produce results at

* The correct value of the factor depending on $\varphi(v)$ is $2 \pi \int r^{2} \varphi r d r$ taken from $r=o$ to $r=\infty$.

I might here make a remark very useful in investigations of this kind, and which I do not remember to have seen elsewhere. If $\varphi(r)$ be such a function of $r$ that it is sensible only with insensible valucs to $r$; and if $f(r)$ be any other function of $r$, finite always when $r$ is finite, and such that the value of $f(r) \times \varphi(r)$ decreases as $r$ increases, $f f(r) . \varphi(r) . d r=0$ when $r=\infty$. 
variance with phænomena almost whatever form we may give to the function $\varphi$. It is however not my intention to pursue them. My object has been merely to show, that M. Laplace's principal and fundamental equations are erroneously deduced from his principles; and consequently that his subsequent conclusions are not cousequences of what he first as. sumes.

It appears to me to be evident that the equations he has produced are more the offspring of a previous knowledge of what they should be from the phrnomena, than of that sound reason which his other works usually manifest. Had the principles he sets out with been given him, namely, that there is such a thing as caloric, which, while strongly repulsive of its own, attracts and is attracted by all other matter; which by some means radiates in extremely minute portions with a great velocity; which attaching itself in considerable quantities to particles of matter overcomes their mutual attraction, and occasions them to stand at the greatest distance the envelope admits from each other; -had, I say, these things only been given him withoutv any knowledge of what the phæenomena require, I would enture to appeal to himself, whether, with his mind so unacquainted, unbiassed, and umprejudiced with the facts in question, his results would not have been very different to what they are. Now, so far from this having been the case with myself, I was not even acquainted with any other law of airs than that of Mariotte, when my theories of collision and of aëriform bodies were first laid down. It was not until some time afterwards that $I$ knew any thing of MM. Gay Lussac and Dalton's law; which, from the awkward synthetical course I pursued, I had some difficulty in demonstrating. Nor was I acquainted with the law that the pressure of a mixture is equal to the sum of the pressures of the component airs, until after my theory had been published; when I accidentally met with it in Biot's Traité de Physique while looking over the theory of vapours. The theory of latent heat, and particularly that of evaporation, was investigated under circumstinces incomparably more disadvantageous. Examples such as these of correct fertility are, I believe, never to be met with where nature and theory are at variance.

It is rather curious that M. Laplace has in effect brought out the same point of absolute cold that $I$ had. He says that all the caloric in a mass of any air at the centigrade zero, is equal to $266 \frac{2}{3}$ centigrade degrees, or to $266^{\frac{2}{3}} \times \frac{9}{5}=480^{\circ} \mathrm{Fahr}$.; the precise quantity that I had given.

With respect however to the Marquis de Laplace's theory and mine, there are cases by which the fite of both may be Vol. 62. No. 303. Jhly 1 sy3. 
decided by experiment. According to his conclusions, the march of an air thermometer is a correct indicator of the increase of caloric; and according to my theory the said march is proportional to the difference of the squares of the true temperatures. If therefore equal weights of any two bodies were mixed at the Fahr. temperatures $32^{\circ}$ and $212^{\circ}$, by his theory the resulting temperature shoull be $122^{\circ}$, the arithmetical

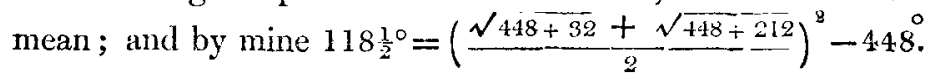
With a greater interval of temperature, a greater difference would exist. Now as far as experiments go on this subject, they are unequivocally in my favour. Every philosopher who has tried such an experiment has, I believe, found the resulting temperature beneath the aritbmetical mean. Even Crawford, who made experiments in a manner the most unaccountable for any one who had hopes of success, found his results less than M. Laplace's theory would give; and by the only two of De Luc's experiments that I have yet seen, there are variations from $M$. Laplace's theory of $3^{\circ}$ and $21^{\circ}$ in defect, and from mine of only $\frac{3}{5}^{\circ}$ and $\frac{1}{10}^{\circ}$ in excess. I have also made some experiments on this subject myself, which accord with the conclusions I have drawn equally as well as De Luc's; but in consequence of being deprived of the means of deciding the value of some corrections through a material accident to my apparatus, I have not yet been able to put them in a condition for publication.

It were much to be wished that some decisive experiments of this kind were undertaken by those who have proper apparatus and opportunities. A determination of the true quantity of deflection from the arithmetical mean of equal weights of the same body mixed at unequal temperatures, would at once settle the grand point respecting the real indications of thermometers; and consequently estublish laws of the highest importance in science.

Cranford, July 19th 1823.

J. Herapath.

XIII. Notices respecting New Books.

Recently published.

7 HE First Part of the Transactions of the Philosophical Society for 1823 has just appeared, and the following are its contents :

The Croonian Lecture. Microscopical Observations on the Suspension of the muscular Motions of the Vibrio Tritici. By; Francis Bauer, Esq.-On Metallic Titanium. By W. H. Wollaston, M.D.-On the Difference of Structure between 